\title{
ILLIQUIDITY AND THE WEALTH EFFECT
}

\author{
Sébastien Galy \\ Concordia University \\ and \\ Konstanz University
}

Tuesday, April 01, 2003 


\section{ILLIQUIDITY AND THE WEALTH EFFECT}

Tuesday, April 01, 2003 


\begin{abstract}
Investors' attitudes towards risk and the resulting impact on prices in financial markets are determined by changes in their wealth. This wealth effect, however, provides a poor explanation of the observed distribution of futures prices for reasonable values of the degree of risk aversion. This paper shows that illiquidity in the futures market, modeled endogenously as a trading cost, increases the strength of the wealth effect for the same degree of risk aversion. The resulting distribution of futures prices presents a more pronounced left fat tail and left skewness than would have been implied by the wealth effect alone.
\end{abstract}




\section{INTRODUCTION}

Although illiquidity is recognized in practice as a major disrupting factor in the functioning of financial markets, its theoretical foundation remains in doubt. This paper proposes a model, with a very general utility framework, in which illiquidity results from the inability of economic agents to share risk at no cost and takes the form of an endogenous trading cost whose importance increases as financial markets come under stress. Illiquidity tends to strengthen the wealth effect, which has traditionally been used to explain the behaviour of risk prices under stress. The wealth effect is the mechanism through which changes in the investors' wealth affect their attitude towards risk and thus prices on the financial markets. This mechanism provides a poor explanation (see Jackwerth and Brown (2001)) of the mean, skewness and kurtosis of the observed distribution of prices especially in the derivatives market for reasonable values of the degree of risk aversion. This paper shows that illiquidity in the futures market, modeled endogenously as a trading cost, increases the strength of the wealth effect by acting as a risk lever. Investors become more risk averse as their wealth falls and therefore ask for ever-higher risk premiums to become the counterparty to a futures contract. With illiquidity, for any decline in wealth, there is more risk to be shared and less willingness to assume it without a lower price and thus a higher return. The increase in futures risk premiums, reflecting greater illiquidity trading costs, is associated with a more pronounced left fat tail and left skewness in the distribution of futures prices in a market dominated by short hedgers than would have been implied by the wealth effect alone. Risk transfers are further studied using comparative statics.

Futures contracts are standardized instruments offered on organized markets. Investors can use them to hedge their risk stemming from changes in the price of the good underlying the contract, while speculators are willing to assume those risks in anticipation of a possible gain. The risks from having a position in the underlying asset are shared through the futures market as well as other derivatives markets. For example, a fast food chain can buy pork belly futures to hedge against the risk of an increase in the price of pork bellies, 
while a pork producer would sell pork belly futures. If both the producer and the fast food chain need to hedge the same amount for the same period, they could enter into a forward agreement, mimicking the futures contract available on organized markets, to exchange pork bellies at a predetermined forward price. Their risk is then defined as perfectly shared and there is no pressure on the futures market assuming that their wealth is solely determined by the price of pork. However, should they have different quantities to hedge, there will be a pressure $^{1}$ on the futures price so as to attract speculators willing to become the counterparty to the excess hedging supply or demand for futures. Hedging pressures are therefore transfers of risks for a price.

Risk transfers become costly when we relax in the investor's optimisation problem the assumption that an investor can initiate a trade of a non-negligible size without having an impact on the market price. This creates endogenously an illiquidity trading cost that increases with the size of the futures trade and by, approximately, the volatility in the underlying spot price. Furthermore, adding illiquidity to the wealth effect changes the distribution of futures prices.

Illiquidity trading costs make the distribution of futures prices fatter in the left tail, left skewed and dependent on the size of futures trades. If futures prices are above their expected value (or arbitrage price), as implied mainly by the conditions prevailing on the underlying good market, then speculators have little wealth at risk and are quite willing to bear that risk cheaply. By contrast, as the underlying good or the rest of their portfolio loses some value, speculators tend to ask for increasing premiums and the distribution of futures prices becomes thicker on the left for low futures prices than on the right for high futures prices. The illiquidity trading cost tends to aggravate the distortions produced by the wealth effect on the distribution of futures prices.

One might argue that Keynes (1930) thoroughly described how speculators become more fearful as they lose their wealth and flee the futures market. However, his analysis

\footnotetext{
${ }^{1}$ This assumes that there are limits to the ability to arbitrage
} 
neglected the enhancing effect of illiquidity. This paper shows that as frightened speculators leave the market these become increasingly illiquid.

The paper is organized as follows. Section I briefly reviews the illiquidity and risk sharing literatures. Section II presents the theoretical model under two central assumptions: (i) futures prices are independent from the quantity traded; and (ii) markets are incomplete. The model is further developed, by relaxing the first assumption in Section III and the second assumption in Section IV. Section V draws on the model findings to analyse the risk sharing mechanism behind the wealth effect and changes in illiquidity.

\section{PREVIOUS WORK ON ILLIQUIDITY AND RISK SHARING}

Illiquidity $^{2}$ is derived endogenously within the microstructure literature generally in the form of a bid-ask spread or transaction costs, stemming mainly from inventory costs introduced by Demsetz (1968), market order processing costs from Garman (1976) and insider trading from Glosten and Milgrom (1985). These models assume the presence of market makers matching the supply and demand who establish bid-ask spreads to cover their operating costs. O'Hara (1994) provides a comprehensive overview of this field. These matching models, however, are of limited use to the vast array of equilibrium and arbitrage models used for pricing and risk management.

Equilibrium or arbitrage models, such as in Ericsson and Renault (2001), take illiquidity as given in the form of an exogenous trading cost and study how it impacts the decisions of investors. Acharya and Pedersen (2002) for example study a four beta CAPM with persistent illiquidity and study its impact on the investors' decision-making. Illiquidity and risk sharing were until now separate lines of research.

Risk sharing is concerned with the possibility for economic agents to exchange risks through financial markets, using derivatives as risk transfer vehicles. In the asset pricing literature, Dumas (1989) shows that when investors have different degrees of risk aversion

\footnotetext{
${ }^{2}$ See Galy (2002) for a more comprehensive review of this field
} 
and suffer a common risk, they must share the aggregate risk. Wang (1994) considers investors that are heterogeneous both in their investment opportunities and access to information. In the absence of information asymmetries, according to Wang (1994), selling by an investor increases the volume and decreases the price, increasing its expected return, as the asset's expected payoff has not changed. This leads other investors to buy the asset so that its price may remain independent of its volume. Risk sharing becomes of interest only if investors cannot correctly assess the asset's expected payoff. This happens when investors have heterogeneous beliefs as in Detemple and Murphy (1994) or asymmetries of information as in Wang (1994). Risk sharing will change depending on the source of the friction, such as non-insurable labor income shocks in Constantinides and Duffie (1996), and frictions or constraints imposed on the investors, such as the lower bound imposed by Grossman and Zhou (1996) on the hedger's wealth which forces them to hedge so as to respect it. This sharing of risks creates a demand for derivatives to shift risk between those who are willing to take on more of risk for a premium and those who must reduce their risk. Risk sharing comes under the broad denomination of 'portfolio insurance demand' in the derivatives literature.

In the derivatives literature, risk sharing among heterogeneous investors therefore creates a role for derivatives as risk transfer vehicles. Grossman and Zhou (1996) studied such an exchange of risk in complete markets and continuous time where one type of hedger is constrained not too lose a given fraction of his initial wealth, creating an asymmetric need to share risk and hence a demand for put options. Franke, Stapleton and Subrahmanyam (1998) show that the degree to which investors face non-hedgeable background risks, such as labor income shocks or shocks to non traded assets, determines the exchange of risks. Finally, Bates (2001) considers the sharing of crash risk or negative stock market jumps and shows that it partially explains why stock options tend to overestimate volatility and the risk of a price jump.

When markets are incomplete, i.e. traders do not have enough uncorrelated assets to hedge all risk sources (Harrison and Pliska (1983) and Duffie and Huang (1985)), the sharing of risks is hampered. In such a context, the supply and demand of financial assets is 
imperfectly elastic as pointed out for example by Leisen (2002), which implies therefore a transfer of risk when trading. Leisen pointed out that derivatives would not be traded if the price of their underlying asset at the next trading date is assumed locally normal and markets are incomplete. Magill and Quinzii (1995) following Keynes (1930) define market incompleteness as a failure of the market to coordinate activities as all futures contract trades cannot be made at a predetermined price due to frictions. This creates a demand for cash to hedge against price uncertainty in addition to futures. The portfolio insurance demand literature extends this result to show that it creates a demand for options.

This paper shows how illiquidity trading costs arise endogenously in an equilibrium model from the inability to share risk freely. This trading cost strengthens the impact of the wealth effect for a given degree of risk aversion result is further generalized to a broad class of utilities in this paper allowing for the wealth effect and thereby altering the distribution of futures prices.

\section{MODEL}

I assume an infinite horizon model with two groups of utility maximizing agents, G producers of commodities and $\mathrm{N}$ speculators. Each agent maximizes the utility he expects from consuming the profits $\pi_{t}$ generated by the sale of a good decided at time 0 but realized only at time $t$. Therefore, the agent faces a problem ${ }^{3}$ each period whereby his cash flows are decided now but realized only $t$ periods in the future. The utility function $V\left(\pi_{t+j}\right), j=1, \ldots, \infty$ is assumed to be increasing and concave in the investor's wealth. The $G+N, i=1, \ldots, G, \ldots, G+N$, producers and speculators may have different degrees of risk aversion.

\footnotetext{
${ }^{3}$ If preferences are separable, it is straightforward to see that the model reverts to a classical maximization of terminal wealth. The fact that the maximization is repeated every period does not change anything as no wealth is accumulated.
} 
The hedger produces at time 0 the quantity $y_{0}$ of goods that will be sold at time $t$ at an uncertain price $p_{t}\left(y_{0}\right)$ that he hedges by selling the quantity $f_{0}$ of futures contracts at a price of $F_{0}$. Producing the good costs him $c\left(y_{0}\right)$ at time 0 but these costs are only realized at time $t$ so that the cash flow from the production of goods decided at time 0 occurs $t$ periods later. The investor's profits at time $t$ equal the revenues generated by the sale of the consumption good minus the costs of production and the cost of hedging the production good by taking short futures contracts positions at time 0 and reversing the position at time t. The profits at time $t$ are therefore given by equation (1):

$$
\pi_{t}=p_{t}\left(y_{0}\right) y_{0}-c\left(y_{0}\right)+f_{0}\left(F_{0}-F_{t}\right)
$$

The investor chooses the number $f_{0}$ of futures contracts so as to maximize his concave utility $V\left(\pi_{t+j}\right), j=1, \ldots, \infty$. I will use the notation $V_{t}^{(i)}$ for the $\mathrm{i}^{\text {th }}$ derivative with respect to profits of the utility function $V\left(\pi_{t+j}\right), j=1, \ldots, \infty$ at time $t$. The first derivative represents the marginal value of an additional dollar for the investor, the second represents the utility's curvature. It can be interpreted as a proxy for risk as can be seen in the Arrow-Pratt measure of risk aversion as well as other global measures of risk.

Differentiating $V\left(\pi_{t+j}\right), j=1, \ldots, \infty$ with respect to $f_{0}$ under the constraint of equation (1) yields equation (2). The futures' price is such that the expected value at time 0 of a dollar measured in terms of marginal utility $E_{0} V_{t}^{(1)}$ invested in the futures contract has a zero return $\left(E_{0} V^{(1)}\left(\left(F_{t}-F_{0}\right) / F_{0}\right)=0\right)$.

$$
E_{0} V_{t}^{(1)}\left(F_{0}-F_{t}\right)=0
$$

A simple transformation $E_{0}\left(V_{t}^{(1)} / V_{0}^{(1)}\right)\left(F_{t}-F_{0}\right)=E_{0} M_{t, 0}\left(F_{t}-F_{0}\right)=0$ shows that equation (2) can be rewritten in terms of the marginal rate of substitution $M_{t, 0}=V_{t}^{(1)} / V_{0}^{(1)}$ between time 0 and time $t$. The marginal rate of substitution gives the price at which the agent would be willing to wait and consume later. It is a classic result that 
if the investor is allowed to trade t period risk free bonds with an interest of $r_{t}$, then the marginal rate of substitution will equal the risk free discount rate $E_{0} M_{t, 0}=1 /\left(1+r_{t}\right)$. The marginal rate of substitution is therefore widely interpreted as the investor's personal risky discount rate $M_{t, 0}=1 /\left(1+\widetilde{r}_{t}\right)$. Equivalently, it is the cash flow deflator used for present valuation but it may be risky as it depends on the investor's preferences

The futures demand and supply $f_{0}$, thereafter referred to as the futures demand, is found by differentiating equation (2) as a function of the futures price $F_{0}$ at time 0 . Hedgers offer futures contracts to speculators who have the same utility maximization problem, but are long in the future contract and have no position in the underlying asset. The resulting futures demand is given by the following equation (3):

$$
f_{0}=\frac{E_{0} V_{t}^{(1)}}{E_{0} V_{t}^{(2)}\left(F_{t}-F_{0}\right)}
$$

The futures demand is a function of the investor's utility. It is an increasing function of the marginal value of profits when hedging and an inverse function of the futures risk premium $F_{t}-F_{0}$

To better understand the demand for futures contracts, I re-express it to introduce the familiar Arrow-Pratt risk aversion. Using the definition of the conditional expectation, conditional covariance ${ }^{4}$ and that of local risk aversion $\rho_{t}=-V_{t}^{(2)} / V_{t}^{(1)}$, the demand for futures contracts (3) becomes a function of the error in predicting the futures price $e_{t}^{F}=E_{0} V_{t}^{(1)}\left(F_{0}-F_{t}\right)-V_{t}^{(1)}\left(F_{0}-F_{t}\right):$

$$
f_{0}=\frac{E_{0} V_{t}^{(1)}}{E_{0} \rho_{t} E_{0} V_{t}^{(1)}\left(F_{0}-F_{t}\right)-\operatorname{Cov}_{0}\left(\rho_{t}, e_{t}^{F}\right)}
$$

The demand is, as before, an increasing function of the marginal value of profits for the investor $E_{0} V^{(1)}$. It is also an inverse function of the futures price change $F_{t}-F_{0}$. This

\footnotetext{
${ }^{4} \operatorname{Cov}_{0}\left(X_{t}, Y_{t}\right)=E_{0}\left(X_{t} Y_{t}\right)-E_{0}\left(X_{t}\right) E_{0}\left(Y_{t}\right)$
} 
relation depends on whether markets are in equilibrium or not. When the futures price is in equilibrium, defined by equation (2), the first element of the denominator disappears from the equilibrium futures demand in equation (4). The second element of the denominator is the conditional covariance of the error in predicting the futures contract value with the ArrowPratt measure of risk aversion. The more the investor's risk aversion is correlated with the error in pricing $e_{t}^{F}$, the higher the hedging demand. In other words, the more fearful the investor becomes of pricing errors, the less he is willing to use futures contracts. Therefore, fear of mispricing is an additional factor driving the demand for futures. These risks are shared when investors trade either to enhance or reduce their exposure. As will be seen in the next section, trading creates endogenously illiquidity in the futures market in the form of a trading cost.

\section{ILLIQUIDITY AS AN ENDOGENOUS TRADING COST}

In this section, we relax the assumption that agents are able to buy or sell any quantity of futures contracts while leaving the futures price unchanged. Friend and Blume (1975) define such markets as illiquid. This changes two things, first the futures price is no longer assumed to be independent of the quantity traded, and secondly each producer initiates a trade thereby creating a price pressure on the futures market that will attract speculators, defined as having no position in the futures contract's underlying asset ${ }^{5}$.

\section{A. MODEL WITH LARGE TRADES}

Relaxing the assumption that the futures price is independent of the quantity traded in the producer's optimization problem changes the futures price. Compared to equation (2) where this assumption was imposed, an additional trading cost appears endogenously. It

\footnotetext{
${ }^{5}$ See the proof of proposition 2 to see why this condition must hold.
} 
equals the quantity of futures traded multiplied by the expected change in the futures price created by the trade.

$$
E_{0} V_{t}^{(1)}\left(F_{t}-F_{0}\right)+f_{0} E_{0} V_{t}^{(1)}\left(\frac{\partial\left(F_{t}-F_{0}\right)}{\partial f_{0}}\right)=0
$$

This trading cost $T C=f_{0} E_{0} V_{t}^{(1)}\left(\partial\left(F_{t}-F_{0}\right) / \partial f_{0}\right)$ is paid by the producer who sells futures for hedging purposes to the speculator buying the futures as a compensation for the sharing in the producer's risk.

\section{B. DERIVING THE TRADING COST}

The derivative $\partial\left(F_{t}-F_{0}\right) / \partial f_{0}$ in equation (5) of the trading cost is unknown. It can be determined directly from equation (2) where it was assumed implicitly to be too small to matter. This assumes that trading a large amount of futures contracts does not change the shape of the demand curve. Differentiating equation (2) as a function of the quantity of futures traded $f_{0}$, I find that the expected value $E_{0} V_{t}^{(1)} \partial\left(F_{t}-F_{0}\right) / \partial f_{0}$ of the differential in terms of marginal utility equals the expected value in terms of risk of a deviation in the futures price $\left(F_{t}-F_{0}\right)^{2}$.

$$
E_{0} V_{t}^{(1)} \frac{\partial\left(F_{t}-F_{0}\right)}{\partial f_{0}}=-E_{0} \rho_{t}\left(V_{t}^{(1)}\left(F_{t}-F_{0}\right)^{2}\right)=E_{0}\left(V_{t}^{(2)}\left(F_{t}-F_{0}\right)^{2}\right)
$$

where risk is measured by the Arrow Pratt measure of risk aversion. Note that the risk of a change in the futures price was shown before to be a determinant of the futures demand.

Having derived the trading cost, it is straightforward to find the price equation of the futures contract by introducing equation (6) into (5). This modified price equation of the futures contract equals the original equation (2) plus an additional trading cost $T C=f_{0} E_{0} \rho_{t}\left(V_{t}^{(1)}\left(F_{t}-F_{0}\right)^{2}\right)$ on the right that lowers the futures price.

$$
E_{0} V_{t}^{(1)}\left(F_{t}-F_{0}\right)-f_{0} E_{0} \rho_{t}\left(V_{t}^{(1)}\left(F_{t}-F_{0}\right)^{2}\right)=0
$$


The demand and supply of futures contracts must now be aggregated to find the futures price in the aggregate equilibrium in the presence of illiquidity trading costs.

\section{EQUILIBRIUM IN AN ILLIQUID FUTURES MARKET}

To find the futures price in the aggregate equilibrium, we must aggregate the supply of and demand for futures across investors assuming a single price will clear the futures market. The $\mathrm{G}$ producers initiate the futures contracts and are therefore the ones paying a trading cost to speculators, who do not have a position in the futures contract's underlying asset. Equation (7) which prices the futures contract can therefore be rewritten to introduce a logical operator $I_{i}$ to separate hedging trades from speculative trades.

$$
E_{0} V_{t, i}^{(1)}\left(F_{t}-F_{0}\right)-I_{i} f_{0, i} E_{0} \rho_{t, i}\left(V_{t, i}^{(1)}\left(F_{t}-F_{0}\right)^{2}\right)=0
$$

$I_{i}=1$ if $i$ is a producer (hedger) and 0 otherwise (speculator)

Using the market clearing condition $\sum_{i=1}^{N+G} f_{0, i}=0$ on the futures on equation (8), we find the equation (9) pricing futures contracts in the presence of illiquidity.

$$
E_{0}\left(\sum_{i=1}^{N+G} V_{t, i}^{(1)}\right)\left(F_{t}-F_{0}\right)-\sum_{i=1}^{G} f_{0, i} E_{0} \rho_{t, i}\left(V_{t, i}^{(1)}\left(F_{t}-F_{0}\right)^{2}\right)=0
$$

The first term on the left of equation (9) is the futures contract's value in the market and the second term on the left is the aggregate illiquidity trading cost that must paid by hedgers in order for speculators to accept such trades. The illiquidity trading cost depends, among other things, on the hedgers' trades and their degree of risk aversion. Equation (9) can be rewritten as equation (10) to show how illiquidity and risk shifting are related using the definition of the conditional covariance to separate the futures risk premium from the aggregate marginal utility.

$$
E_{0}\left(F_{t}-F_{0}\right)=-\frac{\operatorname{Cov}_{0}\left(\sum_{i=1}^{N+G} V_{t, i}^{(1)}, F_{t}-F_{0}\right)}{E_{0}\left(\sum_{i=1}^{N+G} V_{t, i}^{(1)}\right)}+\frac{\sum_{i=1}^{G} f_{0, i} E_{0} \rho_{t, i}\left(V_{t, i}^{(1)}\left(F_{t}-F_{0}\right)^{2}\right)}{E_{0}\left(\sum_{i=1}^{N+G} V_{t, i}^{(1)}\right)}
$$


The futures risk premium or drift $E_{0}\left(F_{t}-F_{0}\right)$ on the left of equation (9) depends on the futures contract's ability to reduce or increase the investors' risk in the futures market. This is measured in equation (9) by the covariance $\operatorname{Cov}_{0}\left(\sum_{i=1}^{N+G} V_{t, i}^{(1)}, F_{t}-F_{0}\right)$ on the right side of the equation between the futures risk premium or drift $F_{t}-F_{0}$ and the marginal value of a dollar for investors in that market $\sum_{i=1}^{N+G} V_{t, i}^{(1)}$. To shift the financial risk of producing with futures contracts, the producers must pay a trading cost (last element on the right of equation (10)) dependent on the size of the futures trades and approximately (see proof 3 ) the expected variance of the futures price for the producers adjusted for their expected degree of risk aversion.

\section{FUTURES PRICE DISTRIBUTION}

Introducing illiquidity makes the futures price distribution at time $\mathrm{t} F_{t}$ fatter on the left tail, more left skewed and dependent on the size of trades by strengthening the wealth effect.

As was seen in equations (9) and (10) and proof 3, illiquidity creates an endogenous trading cost that increases with the size of the futures trades, the expected degree of risk aversion and a measure related to the expected variance of the futures price. Illiquidity increases the strength of the wealth effect, which determines how shocks to producers affect the futures price, and thereby determines its distribution. Following a negative shock to the producer's profit, the wealth effect states that the producer's degree of risk aversion $\rho_{t, i}$ increases (see proof 1), as he is assumed to feel more vulnerable and is said to have a prudential motive $\left(V_{t, i}^{(3)} \leq 0\right)$. This triggers a fall in the futures price as it becomes more desirable to short it for hedging and consequently an increase in the futures expected risk premium $E_{0}\left(F_{t}-F_{0}\right)$ and the marginal value of his profits $V_{t, i}^{(1)}$. 
This, in turn, increases the illiquidity trading cost in the aggregate equilibrium $T C=\sum_{i=1}^{G} f_{0, i} E_{0} \rho_{t, i}\left(V_{t, i}^{(1)}\left(F_{t}-F_{0}\right)^{2}\right)$ as its components, the degree of risk aversion $\rho_{t, i}$, marginal value of profits $V_{t, i}^{(1)}$ and especially the element $\left(F_{t}-F_{0}\right)^{2}$, all increase. This last element is the square of the fall in the futures price resulting from the wealth effect, so that for every fall in the investor's profits, the trading cost increases by even more. The illiquidity trading cost increases therefore the strength of the wealth effect.

Illiquidity pushes therefore the futures price distribution to the left. As for every shock affecting the producer's profits, the futures price is lower than it would be without illiquidity. This assumes that in practice producers, selling futures to hedge, initiate a majority of trades. The futures price distribution is therefore more skewed and fatter on the left tail, than would be the case with only the wealth effect.

The properties of skewness and left fat tail can be deduced mathematically from equation (10). Skewness is a measure of the bias in the expectation and is a scaled function of the third moment of the futures price distribution $\mu_{3}=\left(F_{0}-E_{0} F_{t}\right)^{3}$. From equation (10), the third moment is:

$$
\mu_{3}=\left[E_{0}\left(\sum_{i=1}^{N+G} V_{t, i}^{(1)}\right)\right]^{-3}\left(\operatorname{Cov}_{0}\left(\sum_{i=1}^{N+G} V_{t, i}^{(1)}, F_{t}-F_{0}\right)-\sum_{i=1}^{G} f_{0, i} E_{0} \rho_{t, i}\left(V_{t, i}^{(1)}\left(F_{t}-F_{0}\right)^{2}\right)\right)^{3}
$$

The futures price distribution is skewed $\mu_{3} \neq 0$, as the elements on the right of equation (11) are different from zero. Intuitively, the distribution must be skewed to the left as the futures price today trades at a large discount to its expected price $F_{0}<E_{0} F_{t}$ under pressure from hedgers. The sign of the conditional covariance on the right hand side can be determined by deriving the marginal value of profits as a function of the futures premium conditional on the information available at time 0 , all else equal.

$$
\partial\left(\sum_{i=1}^{N+G} V_{t, i}^{(1)}\right) / \partial\left(F_{t}-F_{0}\right)=-\sum_{i=1}^{N+G} V_{t, i}^{(2)} f_{0, i}
$$


The conditional covariance is therefore positive, as the utility is concave $V_{t, i}^{(2)} \leq 0$, and this more so for the $G$ producers selling futures contracts. The trading cost is positive and the entire right side of equation (11) is therefore negative. The futures price distribution is therefore skewed to the left $F_{0}<E_{0} F_{t}$.

In addition to being skewed, the distribution is fatter on the left tail as described by the fourth moment of the futures distribution $\mu_{4}=\left(F_{0}-E_{0} F_{t}\right)^{4}$. This corresponds to equation (11) with the powers changed from three to four. The fourth moment is, as the third, different from zero implying that the futures price distribution has a fat tail. The fourth moment is larger the higher the futures risk premium implying that the distribution has a fatter left tail.

The futures price distribution is left skewed with a fat left tail even if markets are liquid. These properties of the futures price distribution are enhanced by the presence of illiquidity. In essence, a Keynesian run (investors become increasingly fearful as their losses accumulate and leave the market) out of the futures market takes the liquidity out of the futures market. This implies in practice that one needs a lower degree of risk aversion to obtain these properties of the futures price distribution. These results depend however on the assumption that markets are incomplete.

\section{WHEN ILLIQUIDITY TRADING COSTS CEASE TO MATTER: CONVERGENCE TO COMPLETE MARKETS}

In this section, we show that illiquidity is a property of incomplete markets, which disappears as competing hedging products complete the financial markets, assuming that there are an infinite number of risk sources as well as an infinite number of assets available to complete the market.

Illiquidity trading costs are relevant only if the supply and demand curves are not perfectly elastic. As can be seen in equation (5), the derivative $\partial\left(F_{t}-F_{0}\right) / \partial f_{0}$ would then 
equal zero by definition and the trading cost would disappear. If a perfect substitute could be found by a replication or arbitrage strategy, then it is a classic result that the supply and demand must be perfectly elastic, as investors would switch from one good to the other whenever one market would come under trading pressure. The futures price would therefore be independent of the quantity traded. Illiquidity trading costs would then disappear, as the derivative $\partial\left(F_{t}-F_{0}\right) / \partial f_{0}$ within the definition of the trading cost $T C=f_{0} E_{0} V_{t}^{(1)}\left(\partial\left(F_{t}-F_{0}\right) / \partial f_{0}\right)$ equals zero. A futures market is therefore liquid when the supply and demand curves are perfectly elastic. Equivalently, there is no perfect substitute for the futures contract that could replicate its payoff, as would be the case by taking opposite positions on a call and a put with the same strike price on the same underlying commodity.

This ignores however that other substitute products are available for hedging. Proposition 1, derived in the appendix, shows that, as more options are available for hedging or speculation, the elasticity of the supply and demand curves increases as for every increase in the futures price, on can buy other hedging products as imperfect substitutes.

\section{Proposition 1: Convergence to market completeness}

Let $N$ be the number of options available in the market. Let the number of risk sources that influence spot prices be infinite. For a given futures price $F_{0}$ and quantity of futures $f_{0}$ :

a) The futures' supply and demand curves become more elastic as more options become available for hedging. Equivalently, the slope increases as the price and quantity are taken as given.

b) The slope of the futures curve is indeterminate when there is an infinite source of options to hedge an infinite source of risks.

$\lim _{N \rightarrow \infty} \partial f_{0} / \partial F_{0}=$ Indeterminate 
The slopes of the supply and demand curves become indeterminate as illustrated in figure 1, in the limit when markets are complete, and the supply and demand become impervious to futures price changes. This translates graphically below into curves that increasingly flatten as the markets become more complete.

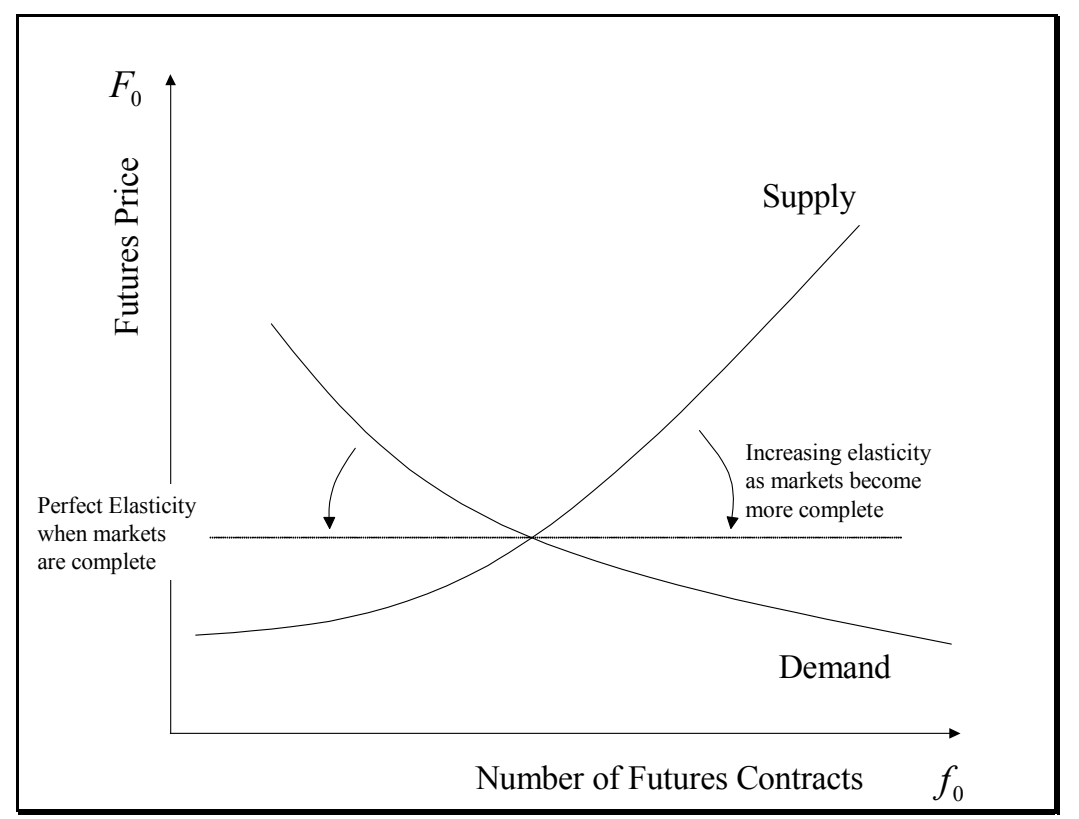

Figure 1: Irrelevance of supply and demand when markets are complete

As the markets become more complete, the supply and demand become more elastic so that trading has an increasingly smaller impact on the futures price.

The illiquidity trading cost declines as financial markets become more complete and sharing risk becomes less relevant. The concept of risk sharing and consecutive illiquidity trading costs are studied using comparative statics in the next section.

\section{RISK SHARING PROPOSITIONS}

In this section, I study risk sharing or changes in the attitude towards risk that generate prices changes through the wealth effect and the illiquidity trading costs. The attitude towards risk will be measured by the degree of risk aversion and prudence. Risk aversion $\rho_{t, i}=-V_{t, i}^{(2)} / V_{t, i}^{(1)}$ measures the investor's willingness to take risks when faced with uncertain profits. It measures the curvature of the utility as a function of profits and is 
positive, as the utility is assumed concave as a function of profits. The more curved it is, the more certain outcomes are preferred to uncertain ones. The degree of prudence $p_{t, i}=-V_{t, i}^{(3)} / V_{t, i}^{(2)}$, sometimes called precaution, measures the investor's willingness to bear risk as his profits or wealth changes (see proof 1).

When the utility function is specified, risk sharing can be studied by comparing graphically how the payoff of a derivative varies as a function of the underlying asset price. If the graph is nonlinear and high for low states, that is these states are more expensive, then there is clearly an excess demand to hedge against these states, or so argues the portfolio insurance literature. As the utility function remains unspecified beyond the hypothesis that it is an increasing and concave function of profits, I use comparative statics ${ }^{6}$ to see how risk alters both the price of and demand for futures contracts.

As we have seen, producers have risks from production, which cannot be hedged away and must be shared with the market. This implies a wealth effect and illiquidity trading costs. In this section, we will show in proposition 2 that this risk sharing puts pressure on the futures risk premium implying that they will tend to decrease (contango) or increase (normal backwardation) over time ${ }^{7}$, with investors willing to buy or sell depending on their level of prudence. We will show in proposition 3 that this problem becomes acute in a high-risk situation such as a crash as there is an ever-increasing demand for hedging as hedgers find themselves more at risk. If investors in the futures market have non-separable preferences, in that the utility derived from tomorrow's profits cannot be separated from today's, then futures contracts become more expensive as investors care about how risk is resolved, thereby reducing the use of futures contracts (proposition 4).

\footnotetext{
${ }^{6}$ See Varian (1992) for examples of the comparative statics method

${ }^{7}$ Keynes (1930) first developed the argument that the unwillingness to bear risk creates contango or normal backwardation in the futures prices.
} 


\section{A. COMPENSATION FOR RISK SHARING}

Proposition 2, derived in the appendix, shows that risk transfers create an upward or downward trend for futures prices known as contango and normal backwardation respectively.

Proposition 2: Relation between prudential and risk tolerant motive with contango or normal backwardation

$$
\begin{array}{ll}
F_{t} \geq F_{0} \Rightarrow f_{0} \leq 0 \Rightarrow \operatorname{Cov}_{0}\left(p_{V_{t}} / V_{t}^{(1)}, V_{t}^{(1)}\left(F_{0}-F_{t}\right)\right) \leq 0 & \text { for a speculator } \\
F_{t} \leq F_{0} \Rightarrow f_{0} \geq 0 \Rightarrow \operatorname{Cov}_{0}\left(p_{V_{t}} / V_{t}^{(1)}, V_{t}^{(1)}\left(F_{0}-F_{t}\right)\right) \geq 0 & \text { for a hedger }
\end{array}
$$

Under normal backwardation, futures prices tend to increase over time $F_{t} \geq F_{0}$. Speculators are then willing to share the hedgers' risk $f_{0} \leq 0$ as they are compensated by an increase in the futures price. This implies that a speculator becomes less prudent for every dollar invested as the value of the futures contract increases $\operatorname{Cov}_{0}\left(p_{V_{t}} / V_{t}^{(1)}, V_{t}^{(1)}\left(F_{0}-F_{t}\right)\right) \leq 0$. Hedgers push the futures price down by selling futures at time 0 and increase it at time $t$ by reversing their positions thus offering a risk premium to speculators.

Under contango, futures prices tend to decrease $F_{t} \leq F_{0}$. Hedgers are more than willing to use futures contracts to hedge $f_{0} \geq 0$, as they can transfer risk to speculators and receive a risk premium for it. They become more prudent for every dollar invested as the value of the futures contract increases $\operatorname{Cov}_{0}\left(p_{V_{t}} / V_{t}^{(1)}, V_{t}^{(1)}\left(F_{0}-F_{t}\right)\right) \geq 0$. This unlikely situation $F_{t} \leq F_{0}$ is possible, but selling pressures from hedgers will push the futures price down immediately. Therefore, one cannot have a downward trend or contango without allowing for an excess of long hedgers in the model to push the current futures price upwards. 


\section{B. NONLINEAR RISK SHARING}

Proposition 2 shows that contango or normal backwardation means that investors are willing to share risk if they are compensated. The result that risk sharing creates a pressure on futures prices was confirmed in section III and is further studied in the proposition 3 .

Proposition 3, derived in the appendix, shows how the supply and demand of futures contracts changes with the degree of risk aversion.

Proposition 3: Risk aversion mechanism

$$
\begin{aligned}
& \operatorname{sign}\left\{\partial f_{0} / \partial \rho_{V_{t}}\right\}=-\operatorname{sign}\left\{E_{0} V_{t}^{(1)}\left(F_{0}-F_{t}\right)\right\} \\
& \operatorname{sign}\left\{\partial^{2} f_{0} / \partial \rho_{V_{t}}^{2}\right\}=\operatorname{sign}\left\{E_{0} \rho_{V_{t}} V_{t}^{(1)}\left(F_{t}-F_{0}\right)\right\}
\end{aligned}
$$

When futures prices increase over time $F_{t} \geq F_{0}$ (normal backwardation), hedgers sell futures contracts as their degree of risk aversion increases $\operatorname{sign}\left\{\partial f_{0} / \partial \rho_{V_{t}}\right\} \geq 0$ (as a result of the wealth effect for example) and this at a decreasing rate $\operatorname{sign}\left\{\partial^{2} f_{0} / \partial \rho_{V_{t}}^{2}\right\} \leq 0$. Hence, the price pressure on the futures markets will be strongest, when hedgers feel the most vulnerable or equivalently have a high degree of risk aversion. In the language of Keynes (1930), proposition 3 states that speculators are frightened and flee the market during a crisis. As was shown in section III.D, the futures market becomes less liquid at an increasingly fast pace through the illiquidity trading cost.

\section{DYNAMIC RISK SHARING}

The attitude towards risk has been described by the degree of risk aversion to uncertainty in profits at a given point in time and is therefore static. In the next section, we add a temporal or dynamic dimension to the attitude towards risk by introducing nonseparability in the investor's preferences. The investor then cares both about uncertainty in his profits and how this uncertainty resolves itself or equivalently its dynamics. This dynamic 
component of the attitude towards risk is shown to effectively increase the investor's degree of risk aversion, limiting his willingness to share risk, and therefore strengthening the wealth effect.

Non-separability of preferences increases the investor's degree of risk aversion by introducing a dynamic component (proposition 4.1) and decreases the investor's willingness to shift risk through time (proposition 4.3). The difference between the degree of risk aversion under non-separable preferences and that under separable preferences is a function of the elasticity of the marginal rate of substitution through time $\sigma$ and the parameter $\alpha$, which controls the degree to which preferences are non-separable ${ }^{8}$ (proposition 4.4). Therefore, the speculator requires a greater compensation for entering into a futures contract, as the expected value of the futures contract at time $t$ is greater. The contract becomes more expensive through these two mechanisms so that the demand for futures contracts falls.

The attitude towards risk is said to be dynamic if the investors' preferences are not an additive sum of his instantaneous utility. Until now, the investors were assumed to have preferences that were additive or separable so that each period the producer took decisions independently of how it would impact his future instantaneous utility and hence future decisions. The investor's utility function $V\left(\pi_{t+j}\right), j=1, \ldots, \infty$ under non-separable preferences is chosen as a nonlinear sum of instantaneous utilities (13) that reverts to the linear or separable case used before when the parameter $\alpha=0$. The investor's attitude towards time is given by the parameter $\beta$ discounting his instantaneous utilities, while his time horizon is given by the parameter $T_{1}$.

$$
V_{t}=\left[\sum_{i=0}^{T_{1}} \beta^{i} U\left(\pi_{t+i}\right)\right]^{1-\alpha}
$$

The non-separability of the utility of profits across time introduces a dynamic to risk, the investor taking into account how a risky investment will evolve. For example, managers face great anxiety or elation today when undertaking a high-risk project, as they are uncertain

\footnotetext{
${ }^{8}$ If $\alpha=0$ the utility function reverts to one of separable preferences.
} 
not only how it will work out today and tomorrow, but how the risk of that project will evolve as time goes by. The degree of risk aversion under separable preferences corresponds therefore to the one based on the instantaneous utility $\rho_{U_{t}}=-U_{t}^{(2)} / U_{t}^{(1)}$, while that under non-separable preferences is based on the function of the instantaneous utilities $\rho_{V_{t}}=-V_{t}^{(2)} / V_{t}^{(1)}$

Proposition 4.1, proved in the annex, shows that the degree to which preferences are non-separable influences the demand for futures contracts.

\section{Proposition 4.1: Dynamic risk}

$$
\frac{\partial f_{0}}{\partial \alpha} \leq 0 \text { if } F_{t} \leq F_{0} \text { the futures price is decreasing and } \rho_{V}^{2} \geq((1+\alpha) \theta)^{-1}
$$

From proposition 2, we know that this proposition concerns a hedger selling futures contracts as he can both shift his risk and be compensated for it. An increase in dynamic risk, controlled by the parameter $\alpha$, decreases hedging demand for a given level of the instantaneous degree of risk aversion $\rho_{V_{t}}^{2} \geq((1+\alpha) \theta)^{-1}$ where $\theta$ is the difference between the degree of risk aversion under non-separable and separable preferences. An increase in the importance of dynamic risk controlled by $\alpha$ increases the importance of past and future profits on the utility $V\left(\pi_{t+j}\right), j=1, \ldots, \infty$ derived by the investor from his profits. The hedger uses fewer futures contracts in the presence of dynamic risk even though he can shift his risk and be compensated for it.

Proposition 4.2 shows that introducing a dynamic component to the investor's attitude towards risk increases the investor's degree of risk aversion, thereby strengthening the wealth effect.

Proposition 4.2: Relation between static and dynamic risk aversions measures

$$
\rho_{V_{t}}=\rho_{U_{t}}+\frac{\alpha U_{t}^{(1)}}{\sum_{i=0}^{T_{1}} \beta^{i} U\left(\pi_{t+i}\right)}
$$


The Arrow-Pratt measure of risk aversion $\rho_{V_{t}}=-V_{t}^{(2)} / V_{t}^{(1)}$ of the utility with non-separable preferences exceeds the one with separable preferences $\rho_{U_{t}}=-U_{t}^{(2)} / U_{t}^{(1)}$ by a factor $\alpha U_{t}^{(1)} V_{t}^{-1 / 1-\alpha}$ that is positive if $\alpha \geq 0$ and $V\left(\pi_{t+j}, j=1, \ldots, \infty\right) \geq 0$. When preferences are separable $\alpha=0$, the two measures of risks are equal. Under these conditions, assuming separable preferences, and $0<\alpha \leq 1$ for the utility to be concave (see proof 2), is therefore equivalent to increasing the investor's degree of risk aversion. Note that risk aversion under separable preferences can be said to be dynamic as it depends on future utilities or states, while the traditional measure is static.

Proposition 4.3 shows that the increase in risk aversion comes from an unwillingness to shift risk through time when preferences are non-separable.

Proposition 4.3: Relation between the elasticity of the marginal rate of substitution through time $\sigma_{t}$ (EMRST) and the parameter $\alpha$ :

$$
\sigma_{t}=\frac{\partial \ln V_{t}}{\partial \ln \pi_{t}}=(1-\alpha) \frac{\pi_{t} U_{t}^{(1)}}{\sum_{i=0}^{T_{1}} \beta^{i} U\left(\pi_{t+i}\right)}
$$

The elasticity of the marginal rate of substitution through time (EMRST) is a decreasing function of the parameter $\alpha$. The more the investor is concerned about risk resolution, the less he is willing to shift risk through time and hence the higher the risk premium he will require to enter into a futures contract.

The previous set of propositions showed that risk sharing becomes more difficult when introducing a dynamic component to risk. Proposition 4.4 summarizes these results.

Proposition 4.4: Relation between the degrees of absolute risk aversion $\rho_{V_{t}}^{A}, \rho_{U_{t}}^{A}$ and the EMRST $\sigma$

$$
\rho_{V_{t}}^{A}=\rho_{U_{t}}^{A}+\sigma \frac{\alpha}{1-\alpha}
$$


Proposition 4.4 follows directly from propositions 4.2 and 4.3 It shows the dynamic risk aversion $\rho_{V_{t}}^{A}=-V_{t}^{(2)} \pi_{t} / V_{t}^{(1)}$ difference with the static risk aversion $\rho_{U_{t}}^{A}=-U_{t}^{(2)} \pi_{t} / U_{t}^{(1)}$ is a function of the EMRST $(\sigma)$ and the parameter $\alpha$. When the parameter $\alpha$ increases, the ratio $\alpha / 1-\alpha$ increases and the EMRST $\sigma$ decreases (proposition 4.2). The net impact is more clearly seen in proposition 4.2, where the premium increases linearly with $\alpha$. Hence, dynamic risk as measured by $\alpha$ increases the investor's degree of risk aversion by decreasing his willingness to shift risk through time. This dynamic component disappears when preferences are separable $\alpha=0$. 


\section{CONCLUSION}

Risk sharing creates an illiquidity trading cost that strengthens the wealth effect. This in turn increases the fatness of the left tail and skewness of the distribution of futures prices beyond that created by the wealth effect. Risk sharing becomes increasingly difficult as investors find themselves at risk, creating a pressure on the futures prices for speculators to accept the risk unloaded by hedgers. In the presence of non-separable preferences, this mechanism is again strengthened as investors worry about how uncertainty will resolve itself. This paper suggests that illiquidity is proxied by volatility and that Delta-Vega hedged portfolios should therefore empirically be less sensitive to market pressures, a point left for future research. 


\section{ANNEX}

\section{Proposition 1: Convergence to market completeness}

Let $N$ be the number of options available in the market. Let the number of risk sources that influence spot prices be infinite. For a given futures price $F_{0}$ and quantity of futures $f_{0}$ :

a) The futures' supply and demand curves become more elastic as more options become available for hedging. Equivalently, the slope increases as the price and quantity are taken as given.

b) The slope of the futures curve is indeterminate when there is an infinite source of options to hedge an infinite source of risks.

$\lim _{N \rightarrow \infty} \partial f_{0} / \partial F_{0}=$ Indeterminate

Proof proposition 1:

To prove proposition 1, we must first find the slope of the futures demand. The demand function (3) is derived as a function of the futures price.

$$
\begin{aligned}
& \frac{\partial f_{0}}{\partial F_{0}}=\frac{-f_{0} E_{0} V_{t}^{(2)}\left(E_{0} V_{t}^{(2)}\left(F_{t}-F_{0}\right)\right)-E_{0} V_{t}^{(1)}\left(f_{0} E_{0} V_{t}^{(3)}\left(F_{t}-F_{0}\right)-E_{0} V_{t}^{(2)}\right)}{\left(E_{0} V_{t}^{(2)}\left(F_{t}-F_{0}\right)\right)^{2}} \\
& (3)=>\frac{\partial f_{0}}{\partial F_{0}}=\frac{-E_{0} V_{t}^{(1)}\left(E_{0} V_{t}^{(2)}\right)-E_{0} V_{t}^{(1)}\left(f_{0} E_{0} V_{t}^{(3)}\left(F_{t}-F_{0}\right)-E_{0} V_{t}^{(2)}\right)}{\left(E_{0} V_{t}^{(2)}\left(F_{t}-F_{0}\right)\right)^{2}} \\
& (3)=>\frac{\partial f_{0}}{\partial F_{0}}=f_{0} \frac{-E_{0} V_{t}^{(2)}-f_{0} E_{0} V_{t}^{(3)}\left(F_{t}-F_{0}\right)+E_{0} V_{t}^{(2)}}{\left(E_{0} V_{t}^{(2)}\left(F_{t}-F_{0}\right)\right)} \\
& \frac{\partial f_{0}}{\partial F_{0}}=-f_{0}^{2} \frac{E_{0} V_{t}^{(3)}\left(F_{t}-F_{0}\right)}{E_{0} V_{t}^{(2)}\left(F_{t}-F_{0}\right)}
\end{aligned}
$$

using equation (40), derived as part of the proof of proposition 2, we have therefore:

$$
\frac{\partial f_{0}}{\partial F_{0}}=-2 f_{0} \frac{E_{0} V_{t}^{(2)}}{E_{0} V_{t}^{(2)}\left(F_{t}-F_{0}\right)}
$$




$$
\frac{\partial f_{0}}{\partial F_{0}}=-2 \frac{E_{0} V_{t}^{(1)} E_{0} V_{t}^{(2)}}{\left(E_{0} V_{t}^{(2)}\left(F_{t}-F_{0}\right)\right)^{2}}
$$

The hedger has now a portfolio of $\mathrm{N}$ derivatives on the underlying product giving each a different payoff $g_{i}\left(p\left(y_{t}\right), ..\right)$ at maturity. The sources of uncertainty on the spot price remain unspecified and may be multiple.

$$
\pi_{t, N}=p\left(y_{t}\right) y_{0}-c\left(y_{0}\right)-f_{0}\left(F_{t}-F_{0}\right)-\sum_{i=1}^{N} f_{0, i} g_{i}\left(p\left(y_{t}\right), . .\right)
$$

Proof of proposition 1.a):

if $\left(F_{t}-F_{0}\right) \leq 0$ we just showed that $0 \geq V_{t}^{(2)}\left(\pi_{t, N+1}\right) \geq V_{t}^{(2)}\left(\pi_{t, N}\right)$

Using equation (19), the inverse of the price elasticity is

$$
\varepsilon_{F_{0}, f_{0}}^{-1}=\frac{\partial f_{0}}{\partial F_{0}} \frac{F_{0}}{f_{0}}=-2 F_{0} \frac{E_{0} V_{t}^{(2)}}{E_{0} V_{t}^{(2)}\left(F_{t}-F_{0}\right)}
$$

using the equilibrium demand of futures (3) into (21)

$$
\varepsilon_{F_{0}, f_{0}}^{-1}=\frac{\partial f_{0}}{\partial F_{0}} \frac{F_{0}}{f_{0}}=-2 F_{0} f_{0} \frac{E_{0} V_{t}^{(2)}}{E_{0} V_{t}^{(1)}}
$$

Note the more options are available, the more the utility changes so that the demand for futures contracts, which depends on the first and second degree of the utility, changes as other options become available. For a given price and quantity of futures in equilibrium at time $0, \mathrm{I}$ find how the elasticity of the curve changes. The introduction of a new good changes not only the shape of the curve as measured by elasticity but its position.

$$
\frac{\left.\varepsilon_{F_{0}, f_{0}}^{-1}\right|_{N+1}}{\left.\varepsilon_{F_{0}, f_{0}}^{-1}\right|_{N}}=\frac{E_{0} V_{t}^{(1)}\left(\pi_{t, N}\right)}{E_{0} V_{t}^{(1)}\left(\pi_{t, N+1}\right)} \frac{E_{0} V_{t}^{(2)}\left(\pi_{t, N+1}\right)}{E_{0} V_{t}^{(2)}\left(\pi_{t, N}\right)}
$$

As the utility is concave $V_{t}^{(2)}() \leq$.0 , then $V_{t}^{(1)}($.$) is a decreasing function so that:$

$$
E_{0} V_{t}^{(1)}\left(\pi_{t, N+1}\right) \geq E_{0} V_{t}^{(1)}\left(\pi_{t, N}\right)
$$


Whether $\left(F_{t}-F_{0}\right) \geq 0$ or $\left(F_{t}-F_{0}\right) \leq 0$, I show in the demonstration of proposition 1.1 that it implies: $E_{0} V_{t}^{(2)}\left(\pi_{t, N+1}\right) \leq E_{0} V_{t}^{(2)}\left(\pi_{t, N}\right)$

So that equation $(23)=>\frac{\left.\varepsilon_{F_{0}, f_{0}}^{-1}\right|_{N+1}}{\left.\varepsilon_{F_{0}, f_{0}}^{-1}\right|_{N}} \leq 1=>\left.\varepsilon_{F_{0}, f_{0}}\right|_{N+1} \geq\left.\varepsilon_{F_{0}, f_{0}}\right|_{N}$

The elasticity of the supply or demand curve increases the more options are available.

Proof of proposition 1.b):

To find the limit of the slope given by equation (19), I first find the limit of the denominator and numerator. The proofs of propositions 1.a and 1.b assume the price and quantity to be constant.

1) I find the limit of the denominator $\lim _{N \rightarrow \infty} E_{0}\left(V_{t}^{(2)}\left(\pi_{t, N+1}\right)\right)\left(F_{t}-F_{0}\right)=$ ?

$E_{0}\left(V_{t}^{(2)}\left(\pi_{t, N+1}\right)\right)\left(F_{t}-F_{0}\right)=E_{0}\left(V_{t}^{(2)}\left(\pi_{t, N}-f_{0, N+1} g_{N+1}().\right)\right)\left(F_{t}-F_{0}\right)$

- if $\left(F_{t}-F_{0}\right) \leq 0$ then by proposition $2, V_{t}^{(3)} \leq 0$, then $V_{t}^{(2)}($.$) is a decreasing$ function of profits so that, supposing that the additional options are used for speculating $\left(f_{0, N+1} g_{N+1}() \leq 0.\right)$ :

$V_{t}^{(2)}\left(\pi_{t, N+1}\right) \leq V_{t}^{(2)}\left(\pi_{t, N}\right) \leq 0$

$\Rightarrow \lim _{N \rightarrow \infty} E_{0}\left(V_{t}^{(2)}\left(\pi_{t, N+1}\right)\right)=-\infty$

and as $\left(F_{t}-F_{0}\right) \leq 0=>$

$E_{0}\left(V_{t}^{(2)}\left(\pi_{t, N+1}\right)\right)\left(F_{t}-F_{0}\right) \geq E_{0}\left(V_{t}^{(2)}\left(\pi_{t, N}\right)\right)\left(F_{t}-F_{0}\right) \geq 0$

Hence, the denominator of equation (17) is an increasing function of the number of substitute options available for speculating. In the limit, the denominator therefore converges to infinity.

$\lim _{N \rightarrow \infty} E_{0}\left(V_{t}^{(2)}\left(\pi_{t, N+1}\right)\right)\left(F_{t}-F_{0}\right)=\infty$ 
- if $\left(F_{t}-F_{0}\right) \geq 0$ then by proposition $2, V_{t}^{(3)} \geq 0$, then $V_{t}^{(2)}($.$) is an increasing$ function of profits so that, supposing that the additional options are used for hedging $\left(f_{0, N+1} g_{N+1}() \geq 0.\right)$ :

$V_{t}^{(2)}\left(\pi_{t, N+1}\right) \leq V_{t}^{(2)}\left(\pi_{t, N}\right) \leq 0$

$=>\lim _{N \rightarrow \infty} E_{0}\left(V_{t}^{(2)}\left(\pi_{t, N+1}\right)\right)=-\infty$

and as $\left(F_{t}-F_{0}\right) \geq 0=>$

$$
E_{0}\left(V_{t}^{(2)}\left(\pi_{t, N+1}\right)\right)\left(F_{t}-F_{0}\right) \leq E_{0}\left(V_{t}^{(2)}\left(\pi_{t, N}\right)\right)\left(F_{t}-F_{0}\right) \leq 0
$$

Hence, the denominator of equation (17) is a decreasing function of the number of substitute options available for hedging. In the limit, the denominator therefore converges to zero.

$\lim _{N \rightarrow \infty} E_{0}\left(V_{t}^{(2)}\left(\pi_{t, N+1}\right)\right)\left(F_{t}-F_{0}\right)=0$

2) I find the limit of the numerator: $\lim _{N \rightarrow \infty} E_{0} V_{t}^{(1)} E_{0} V_{t}^{(2)}=$ ?

If $\left(F_{t}-F_{0}\right) \leq 0$ or $\left(F_{t}-F_{0}\right) \geq 0$, we just showed that:

$V_{t}^{(2)}\left(\pi_{t, N+1}\right) \leq V_{t}^{(2)}\left(\pi_{t, N}\right) \leq 0=>\lim _{N \rightarrow \infty} E_{0}\left(V_{t}^{(2)}\left(\pi_{t, N+1}\right)\right)=-\infty=>$

$\lim _{N \rightarrow \infty} E_{0}\left(V_{t}^{(2)}\left(\pi_{t, N+1}\right)\right) E_{0}\left(V_{t}^{(1)}\left(\pi_{t, N+1}\right)\right)=-\infty .0=I D$ (Indeterminate)

Since the utility is concave $V_{t}^{(2)}() \leq$.0 then $V_{t}^{(1)}($.$) is a decreasing function.$

If $\left(F_{t}-F_{0}\right) \geq 0 \Rightarrow>\leq V_{t}^{(1)}\left(\pi_{t, N+1}\right) \leq V_{t}^{(1)}\left(\pi_{t, N}\right) \Rightarrow \lim _{N \rightarrow \infty} E_{0}\left(V_{t}^{(1)}\left(\pi_{t, N+1}\right)\right)=0$

If $\left(F_{t}-F_{0}\right) \leq 0 \Rightarrow 0 \leq V_{t}^{(1)}\left(\pi_{t, N}\right) \leq V_{t}^{(1)}\left(\pi_{t, N+1}\right) \Rightarrow \lim _{N \rightarrow \infty} E_{0}\left(V_{t}^{(1)}\left(\pi_{t, N+1}\right)\right)=\infty$

Using the results of 1), 2) and equation (19), we have:

if $\left(F_{t}-F_{0}\right) \leq 0=>\lim _{N \rightarrow \infty} \frac{\partial f_{0}}{\partial F_{0}}=-\frac{-\infty . \infty}{\infty}=I D$

if $\left(F_{t}-F_{0}\right) \geq 0=>\lim _{N \rightarrow \infty} \frac{\partial f_{0}}{\partial F_{0}}=-\frac{0 \cdot(-\infty)}{0}=I D$ 
The slope of the supply or demand curves are therefore indeterminate in the limit. In the limit, the two are perfectly elastic or flat so that the quantity and hence the slope cannot be determined. 
Proposition 2: Relation between prudential and risk tolerant motive with contango or normal backwardation

$$
\begin{array}{ll}
F_{t} \geq F_{0} \Rightarrow f_{0} \leq 0 \Rightarrow \operatorname{Cov}_{0}\left(p_{t} / V_{t}^{(1)}, V_{t}^{(1)}\left(F_{0}-F_{t}\right)\right) \leq 0 & \text { for a speculator } \\
F_{t} \leq F_{0} \Rightarrow f_{0} \geq 0 \Rightarrow \operatorname{Cov}_{0}\left(p_{t} / V_{t}^{(1)}, V_{t}^{(1)}\left(F_{0}-F_{t}\right)\right) \geq 0 & \text { for a hedger }
\end{array}
$$

Proof of Proposition 2:

To find the demand for futures contracts, I use the demand for futures (3) and expand its denominator using the definition of the covariance.

$$
f_{0}=\frac{E_{0} V_{t}^{(1)}}{E_{0} \rho_{t} E_{0} V_{t}^{(1)}\left(F_{0}-F_{t}\right)+\operatorname{Cov}_{0}\left(\rho_{t}, V_{t}^{(1)}\left(F_{0}-F_{t}\right)\right)}
$$

Using the first order condition of equilibrium (2), the futures demand in equilibrium is therefore given by,

$$
f_{0}^{\text {equilibrium }}=\frac{E_{0} V_{t}^{(1)}}{\operatorname{Cov}_{0}\left(\rho_{t}, V_{t}^{(1)}\left(F_{0}-F_{t}\right)\right)}
$$

Equation (35) shows an investor in equilibrium will hold futures contracts long if his degree of risk aversion moves in the same direction as the value of the futures contract and short otherwise.

$$
\operatorname{sign}\left\{f_{0}\right\}=\operatorname{sign}\left\{\operatorname{Cov}_{0}\left(\rho_{t}, V_{t}^{(1)}\left(F_{0}-F_{t}\right)\right)\right\}
$$

Therefore, the producer hedges because the value of the futures contract increases when the expected spot price of his goods falls. An investor without a position in the underlying asset is less risk averse when the value of the futures contract increases and is therefore willing to act as a speculator.

If the futures prices are increasing (normal backwardation), then as can be seen in equation (35) using the result of (36), then the speculator is willing to take a long position. If the futures prices are increasing (contango), then as can be seen in equation (35) using the 
result of (36), then the hedger is willing to take a short position. These results are summarized below:

$F_{0}-F_{t} \leq 0 \Rightarrow f_{0} \leq 0$ for a speculator

$F_{0}-F_{t} \geq 0 \Rightarrow f_{0} \geq 0$ for a hedger

To find the impact of the prudential motive on risk taking, I derive equation (2) noted here (36), pricing the futures contract as a function of the futures price $F_{t}$, as a function of the futures position $f_{0}$ and then the futures price $F_{0}$, I obtain equation (37) and then (38):

$E_{0} V_{t}^{(1)}\left(F_{t}-F_{0}\right)=0$

$E_{0} V_{t}^{(2)}\left(F_{t}-F_{0}\right)^{2}=0$

$E_{0} V_{t}^{(2)} 2\left(F_{0}-F_{t}\right)+E_{0} V_{t}^{(3)} f_{0}\left(F_{0}-F_{t}\right)^{2}=0$

Equation (38) can be rewritten in the following manner:

$$
\begin{aligned}
& 2 E_{0}\left(-V_{t}^{(2)}\right)\left(F_{0}-F_{t}\right)=E_{0} V_{t}^{(3)} f_{0}\left(F_{0}-F_{t}\right)^{2} \\
& 2 E_{0} \rho_{t} V_{t}^{(1)}\left(F_{0}-F_{t}\right)=f_{0} E_{0} p_{t} \rho_{t} V_{t}^{(1)}\left(F_{0}-F_{t}\right)^{2} \\
& f_{0}^{2}=2 E_{0} V_{t}^{(1)} / \operatorname{Cov}_{0}\left(\frac{p_{t}}{V_{t}^{(1)}} \rho_{t} V_{t}^{(1)}\left(F_{0}-F_{t}\right), V_{t}^{(1)}\left(F_{0}-F_{t}\right)\right)
\end{aligned}
$$

From the result of equation (36), equation (42) can only hold if the hedger becomes more prudent for every dollar invested as the value of the futures contract increases. Conversely, a speculator becomes less prudent for every dollar invested as the value of the futures contract increases.

$$
\begin{array}{ll}
\operatorname{Cov}_{0}\left(p_{t} / V_{t}^{(1)}, V_{t}^{(1)}\left(F_{0}-F_{t}\right)\right) \geq 0 & f_{0} \geq 0 \\
\operatorname{Cov}_{0}\left(p_{t} / V_{t}^{(1)}, V_{t}^{(1)}\left(F_{0}-F_{t}\right)\right) \leq 0 & f_{0} \leq 0
\end{array}
$$

The proposition 2 therefore holds. 
Proposition 3: Risk aversion mechanism

$$
\begin{aligned}
& \operatorname{sign}\left\{\partial f_{0} / \partial \rho_{t}\right\}=-\operatorname{sign}\left\{E_{0} V_{t}^{(1)}\left(F_{0}-F_{t}\right)\right\} \\
& \operatorname{sign}\left\{\partial^{2} f_{0} / \partial \rho_{t}^{2}\right\}=\operatorname{sign}\left\{E_{0} \rho_{t} V_{t}^{(1)}\left(F_{t}-F_{0}\right)\right\}
\end{aligned}
$$

Proof of Proposition 3:

Deriving the futures demand (supply) of equation (3) as a function of the second derivative of the utility $V_{t}^{(2)}$, I find that:

$$
\frac{\partial f_{0}}{\partial \rho_{t}}=\frac{-E_{0}\left(V_{t}^{(1)}\right) E_{0} V_{t}^{(1)}\left(F_{0}-F_{t}\right)}{\left(E_{0} \rho_{t} V_{t}^{(1)}\left(F_{0}-F_{t}\right)\right)^{2}}
$$

Introducing equation (3) into equation (44), the equation simplifies to:

$$
\frac{\partial f_{0}}{\partial \rho_{t}}=-\frac{f_{0}^{2}}{E_{0} V_{t}^{(1)}} E_{0} V_{t}^{(1)}\left(F_{0}-F_{t}\right)
$$

The utility being increasing, it follows therefore that:

$$
\operatorname{sign}\left\{\partial f_{0} / \partial \rho_{t}\right\}=-\operatorname{sign}\left\{E_{0} V_{t}^{(1)}\left(F_{0}-F_{t}\right)\right\}
$$

Deriving equation (47) as a function of the degree of risk aversion:

$$
\frac{\partial^{2} f_{0}}{\partial \rho_{t}^{2}}=\frac{2\left(E_{0} V_{t}^{(1)}\right)\left(E_{0} V_{t}^{(1)}\left(F_{0}-F_{t}\right)\right)^{2}}{\left(E_{0} \rho_{t} V_{t}^{(1)}\left(F_{0}-F_{t}\right)\right)^{3}}
$$

The utility being increasing, it follows therefore that:

$$
\operatorname{sign}\left\{\partial^{2} f_{0} / \partial \rho_{t}^{2}\right\}=\operatorname{sign}\left\{E_{0} \rho_{t} V_{t}^{(1)}\left(F_{0}-F_{t}\right)\right\}
$$

Hence, from the results of (46) and (49), proposition 3 is proved. 
Proposition 4.1: Dynamic risk

$\frac{\partial f_{0}}{\partial \alpha} \leq 0$ if $F_{t} \leq F_{0}$ the futures price is decreasing and $\rho_{V_{t}}^{2} \geq((1+\alpha) \theta)^{-1}$

Note that the index for risk aversion now depends on whether we are considering the instantaneous utility function $U\left(\pi_{t+j}\right), j=1, \ldots, \infty$ or the utility function $V\left(\pi_{t+j}\right), j=1, \ldots, \infty$.

Proof of Proposition 4.1:

To find the impact of dynamic risk on the use of futures contracts $\partial f_{0} / \partial \alpha$, I must first find $\partial V_{t}^{(1)} / \partial \alpha$ and $\partial V_{t}^{(2)} / \partial \alpha$. The intertemporal utility function under non-separable preferences is given by equation (50). $\alpha$ represents the degree to which present and future utilities are linked for the investor when taking a decision today. When it equals zero preferences are said to be separable as tomorrow's utility is added to today's. $\beta$ is the standard parameter describing the agent's preference for time and $T_{1}$ is the horizon of the investor

$V_{t}=\left[\sum_{i=0}^{T_{1}} \beta^{i} U\left(\pi_{t+i}\right)\right]^{1-\alpha}$

The utility's first derivative is given by equation (51) and its second derivative by equation (53):

$$
\begin{aligned}
& V_{t}^{(1)}=(1-\alpha) U_{t}^{(1)}\left[\sum_{i=0}^{T_{1}} \beta^{i} U\left(\pi_{t+i}\right)\right]^{-\alpha}=(1-\alpha) U_{t}^{(1)} V_{t}^{\frac{-\alpha}{1-\alpha}} \\
& V_{t}^{(2)}=(1-\alpha)\left[U_{t}^{(2)}\left[\sum_{i=0}^{T_{1}} \beta^{i} U\left(\pi_{t+i}\right)\right]^{-\alpha}-\alpha\left(U_{t}^{(1)}\right)^{2}\left[\sum_{i=0}^{T_{1}} \beta^{i} U\left(\pi_{t+i}\right)\right]^{-\alpha-1}\right) \\
& V_{t}^{(2)}=(1-\alpha)\left[U_{t}^{(2)} V_{t}^{\frac{-\alpha}{1-\alpha}}-\alpha\left(U_{t}^{(1)}\right)^{2} V_{t}^{-\frac{1+\alpha}{1-\alpha}}\right]
\end{aligned}
$$


1) $\partial V_{t}^{(1)} / \partial \alpha$ : Deriving the first derivative of the utility (51)as a function of the parameter $\alpha$

$$
\begin{aligned}
& \frac{\partial V_{t}^{(1)}}{\partial \alpha}=-U_{t}^{(1)}\left[\sum_{i=0}^{T_{1}} \beta^{i} U\left(\pi_{t+i}\right)\right]^{-\alpha}+(1-\alpha) U_{t}^{(1)}\left[\sum_{i=0}^{T_{1}} \beta^{i} U\left(\pi_{t+i}\right)\right]^{-\alpha} \ln \left[\sum_{i=0}^{T_{1}} \beta^{i} U\left(\pi_{t+i}\right)\right] \\
& \frac{\partial V_{t}^{(1)}}{\partial \alpha}=U_{t}^{(1)} V_{t}^{\frac{-\alpha}{1-\alpha}}\left(-1+(1-\alpha) \ln \left[\sum_{i=0}^{T_{1}} \beta^{i} U\left(\pi_{t+i}\right)\right]\right)
\end{aligned}
$$

2) $\partial V_{t}^{(2)} / \partial \alpha$ : Deriving the second derivative of the utility (53) as a function of the parameter

$\alpha$

$$
\begin{aligned}
& \frac{\partial V_{t}^{(2)}}{\partial \alpha}= \\
& -\left(U_{t}^{(2)}\left[\sum_{i=0}^{T_{1}} \beta^{i} U\left(\pi_{t+i}\right)\right]^{-\alpha}-\alpha\left(U_{t}^{(1)}\right)^{2}\left[\sum_{i=0}^{T_{1}} \beta^{i} U\left(\pi_{t+i}\right)\right]^{-\alpha-1}\right) \\
& +(1-\alpha)\left(-U_{t}^{(2)} V_{t}^{\frac{-\alpha}{1-\alpha}} \ln V_{t}^{\frac{-\alpha}{1-\alpha}}-\left(U_{t}^{(1)}\right)^{2}\left[\sum_{i=0}^{T_{1}} \beta^{i} U\left(\pi_{t+i}\right)\right]^{-\alpha-1}+\alpha\left(U_{t}^{(1)}\right)^{2} V_{t}^{\frac{-\alpha-1}{1-\alpha}} \ln V_{t}^{\frac{-\alpha-1}{1-\alpha}}\right) \\
& \begin{aligned}
\frac{\partial V_{t}^{(2)}}{\partial \alpha}= & -\left(U_{t}^{(2)} V_{t}^{\frac{-\alpha}{1-\alpha}}-\alpha\left(U_{t}^{(1)}\right)^{2} V_{t}^{\frac{-\alpha-1}{1-\alpha}}\right) \\
& +(1-\alpha)\left(-U_{t}^{(2)} V_{t}^{\frac{-\alpha}{1-\alpha}} \ln V_{t}^{\frac{-\alpha}{1-\alpha}}-\left(U_{t}^{(1)}\right)^{2} V_{t}^{\frac{-\alpha-1}{1-\alpha}}+\alpha\left(U_{t}^{(1)}\right)^{2} V_{t}^{\frac{-\alpha-1}{1-\alpha}} \ln V_{t}^{\frac{-\alpha-1}{1-\alpha}}\right)
\end{aligned} \\
& \frac{\partial V_{t}^{(2)}}{\partial \alpha}=V_{t}^{\frac{-\alpha}{1-\alpha}}\left[-U_{t}^{(2)}+(1-\alpha)\left(-U_{t}^{(2)} \ln V_{t}^{\frac{-\alpha}{1-\alpha}}\right)\right]+ \\
& V_{t}^{\frac{-\alpha-1}{1-\alpha}}\left[\alpha\left(U_{t}^{(1)}\right)^{2}+(1-\alpha)\left(-\left(U_{t}^{(1)}\right)^{2}+\alpha\left(U_{t}^{(1)}\right)^{2} \ln V_{t}^{\frac{-\alpha-1}{1-\alpha}}\right)\right] \\
& \begin{aligned}
\frac{\partial V_{t}^{(2)}}{\partial \alpha}= & -U_{t}^{(2)} V_{t}^{\frac{-\alpha}{1-\alpha}}\left[1+(1-\alpha)\left(\ln V_{t}^{\frac{-\alpha}{1-\alpha}}\right)\right] \\
& +\left(U_{t}^{(1)}\right)^{2} V_{t}^{\frac{-\alpha-1}{1-\alpha}}\left[\alpha+(1-\alpha)\left(-1+\alpha \ln V_{t}^{\frac{-\alpha-1}{1-\alpha}}\right)\right]
\end{aligned}
\end{aligned}
$$

3) $\partial f_{0} / \partial \alpha$ : The demand for futures equation given by equation (3) is differentiated as a function of the parameter $\alpha$ 
$\frac{\partial f_{0}}{\partial \alpha}=\frac{E_{0}\left[U_{t}^{(1)} V_{t}^{-\frac{\alpha}{1-\alpha}}\left(-1+(1-\alpha) \ln V_{t}^{\frac{1}{1-\alpha}}\right)\right] E_{0} V_{t}^{(2)}\left(F_{t_{2}}-F_{0}\right)}{\left(E_{0} V^{(2)}\left(F_{t_{2}}-F_{0}\right)\right)^{2}}$

$\frac{-E_{0}\left(V_{t}^{(1)}\right) E_{0}\left[\left(F_{t_{2}}-F_{0}\right)\left(\begin{array}{l}-U_{t}^{(1)} V_{t}^{\frac{-\alpha}{1-\alpha}}\left[1+(1-\alpha)\left(\ln V_{t}^{\frac{-\alpha}{1-\alpha}}\right)\right] \\ +\left(U_{t}^{(2)}\right)^{2} V_{t}^{\frac{-\alpha-1}{1-\alpha}}\left[\alpha+(1-\alpha)\left(-1+\alpha \ln V_{t}^{\frac{-\alpha-1}{1-\alpha}}\right)\right]\end{array}\right]\right.}{\left(E_{0} V^{(2)}\left(F_{t_{2}}-F_{0}\right)\right)^{2}}$

$\frac{\partial f_{0}}{\partial \alpha}=\frac{E_{0}\left[U_{t}^{(1)} V_{t}^{-\frac{\alpha}{1-\alpha}}\left(-1+\ln V_{t}\right)\right] E_{0} V_{t}^{(2)}\left(F_{t_{2}}-F_{0}\right)}{\left(E_{0} V_{t}^{(2)}\left(F_{t}-F_{0}\right)\right)^{2}}$

$\frac{\left.-E_{0}\left(V_{t}^{(1)}\right) E_{0}\left[\left(F_{t_{2}}-F_{0}\right)\left(-U_{t}^{(1)} V_{t}^{\frac{-\alpha}{1-\alpha}}\left[1-\alpha \ln V_{t}\right]-\left(U_{t}^{(2)}\right)^{2} V_{t}^{\frac{-\alpha-1}{1-\alpha}}\left[1+\alpha(1+\alpha) \ln V_{t}\right)\right]\right)\right]}{\left(E_{0} V_{t}^{(2)}\left(F_{t}-F_{0}\right)\right)^{2}}$

$\frac{\partial f_{0}}{\partial \alpha}=\frac{E_{0}\left[U_{t}^{(1)} V_{t}^{-\frac{\alpha}{1-\alpha}}\left(-1+\ln V_{t}\right)\right] E_{0} V_{t}^{(2)}\left(F_{t}-F_{0}\right)}{\left(E_{0} V_{t}^{(2)}\left(F_{t}-F_{0}\right)\right)^{2}}$

$\frac{\left.-E_{0}\left(V_{t}^{(1)}\right) E_{0}\left[\left(F_{t}-F_{0}\right) V_{t}^{\frac{-\alpha}{1-\alpha}}\left(-U_{t}^{(1)}\left[1-\alpha \ln V_{t}\right]-\left(U_{t}^{(2)}\right)^{2} V_{t}^{\frac{-1}{1-\alpha}}\left[1+\alpha(1+\alpha) \ln V_{t}\right)\right]\right)\right]}{\left(E_{0} V_{t}^{(2)}\left(F_{t}-F_{0}\right)\right)^{2}}$

$\frac{\partial f_{0}}{\partial \alpha}=\frac{E_{0}\left[U_{t}^{(1)} V_{t}^{-\frac{\alpha}{1-\alpha}}\left(-1+\ln V_{t}\right)\right] E_{0} V_{t}^{(2)}\left(F_{t}-F_{0}\right)}{\left(E_{0} V_{t}^{(2)}\left(F_{t}-F_{0}\right)\right)^{2}}$

$\frac{\left.+E_{0}\left(V_{t}^{(1)}\right) E_{0}\left[\left(F_{t}-F_{0}\right) U_{t}^{(1)} V_{t}^{\frac{-\alpha}{1-\alpha}}\left(\left[1-\alpha \ln V_{t}\right]+\frac{1}{U_{t}^{(1)}}\left(U_{t}^{(2)}\right)^{2} V_{t}^{\frac{-1}{1-\alpha}}\left[1+\alpha(1+\alpha) \ln V_{t}\right)\right]\right)\right]}{\left(E_{0} V_{t}^{(2)}\left(F_{t}-F_{0}\right)\right)^{2}}$

Using equation (71) of proposition 4.4

$\frac{\partial f_{0}}{\partial \alpha}=\frac{E_{0}\left[U_{t}^{(1)} V_{t}^{-\frac{\alpha}{1-\alpha}}\left(-1+\ln V_{t}\right)\right] E_{0} V_{t}^{(2)}\left(F_{t}-F_{0}\right)}{\left(E_{0} V_{t}^{(2)}\left(F_{t}-F_{0}\right)\right)^{2}}$
$\left.+E_{0}\left(V_{t}^{(1)}\right) E_{0}\left[\left(F_{t}-F_{0}\right) U_{t}^{(1)} V_{t}^{\frac{-\alpha}{1-\alpha}}\left(\left[1-\alpha \ln V_{t}\right]+U_{t}^{(1)} \rho_{U_{t}}^{2} V_{t}^{\frac{-1}{1-\alpha}}\left[1+\alpha(1+\alpha) \ln V_{t}\right)\right]\right)\right]$
$\left(E_{0} V_{t}^{(2)}\left(F_{t}-F_{0}\right)\right)^{2}$ 
Using equation (68) $\alpha U_{t}^{(1)} V_{t}^{-\frac{1}{1-\alpha}}=\rho_{V_{t}}-\rho_{U_{t}} \equiv \theta \geq 0$ (proof of proposition 4.4)

$$
\begin{aligned}
& \frac{\partial f_{0}}{\partial \alpha}=\frac{1}{\alpha} \frac{E_{0}\left[\theta V_{t}\left(-1+\ln V_{t}\right) \mid E_{0} V_{t}^{(2)}\left(F_{t}-F_{0}\right)\right.}{\left(E_{0} V_{t}^{(2)}\left(F_{t}-F_{0}\right)\right)^{2}} \\
& \frac{+E_{0}\left(V_{t}^{(1)}\right) E_{0}\left[\left(F_{t}-F_{0}\right) \theta V_{t}\left(\left(1+\theta \rho_{U_{t}}^{2}\right)+\alpha \ln V_{t}\left(-1+(1+\alpha) \theta \rho_{U_{t}}^{2}\right)\right]\right.}{\left(E_{0} V_{t}^{(2)}\left(F_{t}-F_{0}\right)\right)^{2}}
\end{aligned}
$$

$\frac{\partial f_{0}}{\partial \alpha} \leq 0$ if the futures contracts' prices are decreasing and $\rho_{V}^{2} \geq \frac{1}{(1+\alpha) \theta}$

Hence proposition 4.1 is proved. 
Proposition 4.3: Relation between the elasticity of the marginal rate of substitution through time $\sigma$ and the parameter $\alpha$ :

$$
\sigma=\frac{\partial \ln V_{t}}{\partial \ln \pi_{t}}=\frac{1-\alpha}{\sum_{i=0}^{T_{1}} \beta^{i} U\left(\pi_{t+i}\right)} \pi_{t} U_{t}^{(1)}
$$

Proof of proposition 4.3:

Using the definition of the utility function from equation (13) it is straightforward to find:

$$
\sigma=\frac{\partial \ln V_{t}}{\partial \ln \pi_{t}}=(1-\alpha) \frac{\pi_{t} U_{t}^{(1)}}{\sum_{i=0}^{T_{1}} \beta^{i} U\left(\pi_{t+i}\right)}
$$

Proposition 4.4: Relation between the degrees of absolute risk aversion $\rho_{V_{t}}^{A}, \rho_{U_{t}}^{A}$ and the EMRST $\sigma$

$$
\rho_{V_{t}}^{A}=\rho_{U_{t}}^{A}+\sigma \frac{\alpha}{1-\alpha}
$$

Note that A means absolute

Proof of proposition 4.4:

Using the definition of the utility function from equation (13) it is straightforward to find:

$$
\begin{aligned}
& V_{t}^{(1)}=(1-\alpha) U_{t}^{(1)}\left[\sum_{i=0}^{T_{1}} \beta^{i} U\left(\pi_{t+i}\right)\right]^{-\alpha}=(1-\alpha) U_{t}^{(1)} V_{t}^{\frac{-\alpha}{1-\alpha}} \\
& V_{t}^{(2)}=(1-\alpha)\left[U_{t}^{(2)} V_{t}^{\frac{-\alpha}{1-\alpha}}-\alpha\left(U_{t}^{(1)}\right)^{2} V_{t}^{-\frac{1+\alpha}{1-\alpha}}\right]
\end{aligned}
$$

We can derive therefore the risk aversion for the utility function from these two equations as: 


$$
\rho_{V_{t}}=-\frac{V_{t}^{(2)}}{V_{t}^{(1)}}=-\frac{U_{t}^{(2)}}{U_{t}^{(1)}}+\alpha U_{t}^{(1)} V_{t}^{-\frac{1}{1-\alpha}}
$$

Using equation (70), the conclusion of the demonstration follows. Note that:

$$
\begin{aligned}
& \Rightarrow \rho_{V_{t}}=\rho_{U_{t}}+\alpha U_{t}^{(1)} V_{t}^{-\frac{1}{1-\alpha}} \Rightarrow \theta \equiv \rho_{V_{t}}-\rho_{U_{t}} \geq 0 \text { if } \alpha \geq 0 \text { and } V_{t} \geq 0 \\
& \alpha U_{t}^{(1)} V_{t}^{-\frac{1}{1-\alpha}}=\rho_{V_{t}}-\rho_{U_{t}} \quad V_{t}=(1-\alpha) \ln \left(\frac{\rho_{V_{t}}-\rho_{U_{t}}}{\alpha U_{t}^{(1)}}\right)
\end{aligned}
$$




\section{Minor sets of proofs:}

Proof 1: Risk aversion is an increasing function of profits if $V^{(3)} \leq 0$ (prudential motive).

$$
\frac{\partial \rho_{t}}{\partial \pi_{t}}=-\frac{V_{t}^{(3)} V_{t}^{(1)}-V_{t}^{(2) 2}}{V_{t}^{(1) 2}}=-\frac{V_{t}^{(3)}}{V_{t}^{(1)}}+\left[-\frac{V_{t}^{(2)}}{V_{t}^{(1)}}\right]^{2}=-\frac{V_{t}^{(3)}}{V_{t}^{(1)}}+\rho_{t}^{2} \neq 0
$$

\section{Proof 2:}

Assume that the utility function $V_{t}$ defined in equation (13) is positive. The instantaneous utility functions $U_{t}$ and the utility function $V_{t}$ are assumed to be concave. The second derivative of the investor's utility function $\left(V_{t}^{(2)}\right)$ is negative if $0 \leq \alpha \leq 1$. Hence, the parameter $\alpha$ must be bounded between 0 and 1 for the hypothesis that the utility is concave to be true.

$$
V_{t}^{(2)}=(1-\alpha)\left[U_{t}^{(2)} V_{t}^{\frac{-\alpha}{1-\alpha}}-\alpha\left(U_{t}^{(1)}\right)^{2} V_{t}^{-\frac{1+\alpha}{1-\alpha}}\right]
$$

\section{Proof 3:}

I show that the trading cost is a function of the investor's expected local risk aversion and the value of profits and approximately the variance in the futures market. If the futures drift is not too great, then the futures price is a good predictor of its value in the future $F_{0} \approx E\left(F_{t}\right)$.

$$
E_{0} \rho_{t}\left(V_{t, i}^{(1)}\left(F_{t}-F_{0}\right)^{2}\right) \approx E_{0}\left(\rho_{t} V_{t, i}^{(1)}\left(F_{t}-E_{0} F_{t}\right)^{2}\right)
$$

Using the definition of the expected covariance, the equation (75) becomes:

$$
\begin{aligned}
& E_{0} \rho_{t}\left(V_{t, i}^{(1)}\left(F_{t}-F_{0}\right)^{2}\right) \approx \\
& E_{0}\left(\rho_{t} V_{t, i}^{(1)}\right) E_{0}\left(\left(F_{t}-E_{0} F_{t}\right)^{2}\right)+\operatorname{Cov}_{0}\left(\rho_{t} V_{t, i}^{(1)},\left(\left(F_{t}-E_{0} F_{t}\right)^{2}\right)\right)
\end{aligned}
$$

Assuming away the conditional covariance on the left side, equation (77) further simplifies to:

$$
E_{0} \rho_{t}\left(V_{t, i}^{(1)}\left(F_{t}-F_{0}\right)^{2}\right) \approx E_{0}\left(\rho_{t} V_{t, i}^{(1)}\right) \times \operatorname{Var}_{0}\left(F_{t}\right)
$$

Therefore, the trading cost is a function for the investor's expected local risk aversion and the value of profits and approximately the variance in the futures market. 
What does the simplification on the covariance imply?

I define the shock in the futures variance $\varepsilon_{t}$ using the definition of expectations by the following equation $\operatorname{Var}_{0}\left(F_{t}\right)=E_{0}\left(\left(F_{t}-E_{0} F_{t}\right)^{2}\right)=\left(F_{t}-E_{0} F_{t}\right)^{2}+\varepsilon_{t}$. Using this definition in equation (79) it becomes:

$E_{0} \rho_{t}\left(V_{t, i}^{(1)}\left(F_{t}-F_{0}\right)^{2}\right) \approx E_{0}\left(\rho_{t} V_{t, i}^{(1)}\right) E_{0}\left(\left(F_{t}-E_{0} F_{t}\right)^{2}\right)+\operatorname{Cov}_{0}\left(\rho_{t} V_{t, i}^{(1)}, \varepsilon_{t}\right)$

Hence removing the covariance is equivalent to assuming that shocks to the variance of futures prices have no impact on risk aversion and marginal utility and consequently on the futures price. 


\section{REFERENCES}

Bates D., 2001, The Market for Crash Risk, National Bureau of Economic, Research Working Paper 8557.

Brown D., and J. Jackwerth, 2001, The Pricing Kernel Puzzle: Reconciling Index Option Data and Economic Theory, University of Wisconsin at Madison, Working Paper.

Constantinides, G., and D. Duffie, 1996, Asset Pricing with Heterogeneous Consumers, Journal of Political Economy, 104, 219-240.

Demsetz H., 1968, The Cost of Transacting, Quarterly Journal of Economics, 82, 33-53.

Detemple J., and S. Murphy, 1994, Intertemporal Asset Pricing with Heterogeneous Beliefs, Journal of Economic Theory, 62, 294-320.

Duffie D., and C. Huang, 1985, Implementing Arrow-Debreu Equilibria by Continuous Trading of Few Short-Lived Securities, Econometrica, 53, 1337-1356.

Dumas B., 1989, Two-Person Dynamic Equilibrium in the Capital Market, Review of Financial Studies, 2, 157-188.

Franke G., Stapleton R., and M. Subrahmanyam, 1998, Who Buys and who Sells Options: The Role of Options in an Economy with Background Risk, Journal of Economic Theory, 82, 89-109.

Friend I., and M. Blume, 1975, The Demand for Risky Assets, American Economic Review, 65(5), $900-922$.

Ericsson J., and O. Renault, 2001, Liquidity and Credit Risk, FAME-International Center for Financial Asset Management and Engineering, Research Paper 42.

Garman M., 1976, Market Microstructure, Journal of Financial Economics, 3, 257-275.

Grossman S., and Z. Zhou, 1996, Equilibrium Analysis of Portfolio Insurance, Journal of Finance, 51, 1379-1403.

Glosten L. and P. Milgrom, 1985, Bid, Ask, and Transaction Prices in a Specialist Market with Heterogeneously Informed Traders, Journal of Financial Economics, 14, 71-100. 
Harrison J., and S. Pliska, 1983, A stochastic Calculus Model of Continuous Trading: Complete Markets, Stochastic Processes and their Applications, 15, 313-316.

O’Hara M., 1994, Market Microstructure Theory, Oxford: Blackwell Publishing.

Jackwerth J., 2000, Recovering Risk Aversion from Option Prices and Realized Returns, Review of Financial Studies, 13, 433-451.

Keynes J., 1930, A Treatise on Money, Vol. II (McMillan, London).

Leisen D., 2002, Current Option Pricing Models are Inconsistent with Trade, Working Paper, McGill University.

Magill M., and M. Quinzii, 1996, Theory of incomplete markets, London: MIT Press.

Varian H., 1992, Intermediate Microeconomic, A Modern Approach, Norton.

Wang J., 1994, A Model of Competitive Stock Trading Volume, Journal of Political Economy, 102, 127-168. 
